\title{
pH and Antimicrobial Activity of Portland Cement Associated with Different Radiopacifying Agents
}

\author{
Juliane Maria Guerreiro-Tanomaru, Ana Lívia G. Cornélio, Carolina Andolfatto, \\ Loise P. Salles, and Mário Tanomaru-Filho
}

Department of Restorative Dentistry, Araraquara Dental School, São Paulo State University (UNESP), 14801-385 Araraquara, SP, Brazil

Correspondence should be addressed to Mário Tanomaru-Filho, tanomaru@uol.com.br

Received 29 June 2012; Accepted 13 September 2012

Academic Editors: F. Cairo and D. Grenier

Copyright (C 2012 Juliane Maria Guerreiro-Tanomaru et al. This is an open access article distributed under the Creative Commons Attribution License, which permits unrestricted use, distribution, and reproduction in any medium, provided the original work is properly cited.

Objective. The aim of this study was to evaluate the antimicrobial activity and $\mathrm{pH}$ changes induced by Portland cement (PC) alone and in association with radiopacifiers. Methods. The materials tested were pure PC, PC + bismuth oxide, PC + zirconium oxide, $\mathrm{PC}+$ calcium tungstate, and zinc oxide and eugenol cement (ZOE). Antimicrobial activity was evaluated by agar diffusion test using the following strains: Micrococcus luteus, Streptococcus mutans, Enterococcus faecalis, Pseudomonas aeruginosa, and Candida albicans. After 24 hours of incubation at $37^{\circ} \mathrm{C}$, inhibition of bacterial growth was observed and measured. For $\mathrm{pH}$ analysis, material samples $(n=10)$ were placed in polyethylene tubes and immersed in $10 \mathrm{~mL}$ of distilled water. After $12,24,48$, and 72 hours, the $\mathrm{pH}$ of the solutions was determined using a pH meter. Results. All microbial species were inhibited by the cements evaluated. All materials composed of $\mathrm{PC}$ with radiopacifying agents promoted $\mathrm{pH}$ increase similar to pure Portland cement. ZOE had the lowest $\mathrm{pH}$ values throughout all experimental periods. Conclusions. All Portland cement-based materials with the addition of different radiopacifiers (bismuth oxide, calcium tungstate, and zirconium oxide) presented antimicrobial activity and $\mathrm{pH}$ similar to pure Portland cement.

\section{Introduction}

The ideal root-end filling material should present certain characteristics, such as ability to seal the root canal system, dimensional stability in the presence of humidity, and radiopacity. Equally important are its ability to induce repair, antimicrobial action, and biocompatibility. All these properties contribute towards the success of endodontic surgery [1].

Since its introduction as a root-end filling material in 1993, the clinical applications of mineral trioxide aggregate (MTA) have been expanded. Presently, MTA is also used as a reparative cement due to its alkaline $\mathrm{pH}$ [2]. The mechanism of action of MTA is similar to that of calcium hydroxide. However, the manipulation and insertion of this cement into retrograde preparations are extremely difficult. Yet another disadvantage of MTA is its high cost [3].
Several studies have evaluated Portland cement (PC) as an alternative to MTA $[4,5]$. One of the limitations of PC is its low radiopacity, requiring addition of a radiopacifier prior to use. Bismuth oxide, the radiopacifying agent present in MTA, is not considered ideal by some authors. A number of studies have shown that this radiopacifier interferes with the mechanical stability of the cement by increasing its porosity [6] and also that it may negatively affect MTA's biological properties [7]. With this in mind, alternative radiopacifiers have been investigated. Bortoluzzi et al. [8] have studied several radiopacifying agents (bismuth oxide, barium sulfate, iodoform, and zirconium oxide) that may be combined with PC. Gomes Cornélio et al. [9] investigated the association of different radiopaque substances with PC using Murine periodontal ligament cells (mPDL) and rat osteosarcoma cells (ROS 17/2.8) and did not observe 
evidence of cytotoxicity when the cement was mixed with bismuth oxide, zirconium oxide, or calcium tungstate.

Therefore, promising alternatives as radiopacifying agents for PC have been proposed. Now, it is essential to assess how these associations might affect other important properties of sealing cements, such as $\mathrm{pH}$ and antimicrobial action. Antimicrobial action and ability to induce formation of mineralized tissue are both dependent on alkaline $\mathrm{pH}$. These properties have already been thoroughly investigated in pure PC [10].

The aim of the present study was to evaluate and compare the antimicrobial action and $\mathrm{pH}$ changes promoted by PC alone and in association with different radiopacifying agents (bismuth oxide, calcium tungstate, and zirconium oxide).

\section{Materials and Methods}

2.1. Agar Diffusion Assays. The materials and associations investigated are presented in Table 1. PC and associations were manipulated on sterile glass slabs at a ratio of $1 \mathrm{~g}$ of powder to $320 \mu \mathrm{L}$ of water. ZOE cement was manipulated at a ratio of $1 \mathrm{~g}$ of powder to $0.2 \mathrm{~g}$ of eugenol.

Antimicrobial activity was evaluated by agar diffusion test using different microorganisms (Table 2). Inocula of each strain were prepared by suspending cells after growth on plates with Brain Heart Infusion Agar or Sabouraud broth (C. albicans). Then, they were incubated at $37^{\circ} \mathrm{C}$ for 24 hours.

Evaluation of the antimicrobial activity was carried out by the agar well diffusion method, using the double agar layer technique. All assays were conducted in triplicate. A base layer was prepared by placing $12 \mathrm{~mL}$ sterile culture medium cooled to $50^{\circ} \mathrm{C}$ onto sterile Petri dishes measuring $15 \times$ $150 \mathrm{~mm}$. The seed layer was prepared by suspending the inoculum in culture medium at $50^{\circ} \mathrm{C}$ to a final concentration of $10^{6} \mathrm{CFU} / \mathrm{mL}$. Once the base layer had solidified, $8 \mathrm{~mL}$ of the seed layer were added to the dishes.

After solidification of the seed layer, wells were formed by punching holes on the agar using sterile aluminum cylinders measuring $4 \mathrm{~mm}$ in diameter. The placement of the holes was equidistant and $15 \mathrm{~mm}$ from the plate edge. Wells were then completely filled with PC and the associations of PC with the different radiopacifiers to be evaluated.

The plates were kept at room temperature for 2 hours to allow prediffusion of the materials, then incubated at $37^{\circ} \mathrm{C}$ for 24 hours. Following the incubation period, aliquots $(5 \mathrm{~mL})$ of agar TTC (triphenyl tetrazolium chloride-Merck KgaA, Darmstadt, Germany) gel were added to aid the identification of viable cells and allow optimal visualization of the zones of inhibition. Agar TTC was prepared by mixing liquified agar (Difco) with $0.05 \%$ TTC to a concentration of $1.0 \%$. After being added to the plates, the gel was allowed to solidify and plates were incubated once again for 30 minutes at $37^{\circ} \mathrm{C}$.

Images of the well-illuminated Petri dishes against a blue background, to contrast with the red color of the viable colonies, were digitized, and the diameters of the zones of inhibition around each well were measured using the Image Tool software (UTHSCSA Image Tool for Windows, version $3.0)$.
2.2. Evaluation of the $\mathrm{pH}$. For the $\mathrm{pH}$ analyses, 10 standardized polyethylene tubes measuring $10 \mathrm{~mm}$ in length and $1.5 \mathrm{~mm}$ in diameter were prepared for each material tested, totaling 50 tubes. The materials tested were pure Portland cement (PC, Votorantim, SP, Brazil), PC in association with different radiopacifiers: $\mathrm{PC}+$ bismuth oxide, $\mathrm{PC}+$ zirconium oxide, and PC + calcium tungstate (all radiopacifying agents were obtained from Sigma Aldrich, St Louis, MO), and zinc oxide and eugenol cement (ZOE).

Immediately after manipulation of the materials, the tubes were filled and both ends were wiped. Then, each tube was radiographed to ensure adequate and complete filling with the materials. After that, tubes were placed in lidded flasks (JProlab, São José dos Pinhais, PR, Brazil) containing $10 \mathrm{~mL}$ of distilled water with neutral $\mathrm{pH}(\mathrm{pH}$ previously measured $=6.5$ ) and maintained at $37^{\circ} \mathrm{C}$. After $12,24,48$, and 72 hours, the water $\mathrm{pH}$ was measured using a DMPH-2 pH meter (Digimed, São Paulo, SP, Brazil). The device was previously calibrated using buffer solutions with $\mathrm{pH} 4,7$, and 10 . Throughout the experiment, the $\mathrm{pH}$ meter was periodically recalibrated using the same solutions. Measurements were conducted in an environment with controlled and constant temperature of $25^{\circ} \mathrm{C}$. The $\mathrm{pH}$ of the water from a flask containing only distilled water and an empty tube was measured at all experimental periods.

Results were subjected to a normality test and, subsequently, to ANOVA for comparisons among the different groups and to Tukey's multiple comparisons test. The significance level was set at 5\%.

\section{Results}

3.1. Agar Diffusion Assays. The results demonstrated that all microbial species were inhibited by the cements evaluated. Generally, the inhibition haloes were lower for E. faecalis, $S$. mutans, and $P$. aeruginosa (except for ZOE). The means and standard deviations observed for the antimicrobial action of each material are presented in Table 3.

3.2. Evaluation of the $p H$. The means and standard deviations for the $\mathrm{pH}$ values of the cements at each experimental period are presented in Table 4. The results demonstrated that all radiopacifying agents tested promoted $\mathrm{pH}$ increase similar to pure Portland cement (mean 10.2) and that addition of radiopacifiers to $\mathrm{PC}$ did not affect this property. $\mathrm{ZOE}$ presented the lowest $\mathrm{pH}$ values at all experimental periods.

\section{Discussion}

The agar diffusion test (ADT) is commonly used to assess the antimicrobial action of dental materials [11]. This method allows evaluation of the antimicrobial properties of different substances (cements, intracanal medications, and irrigating solutions, among others) against a large number of microbial strains, at various concentrations. The microorganisms used in the present work have been implicated in cases of persistent infection or treatment [12]. Nagayoshi et al. [13] 
TABLE 1: Composition and manufacturer of the materials used in this study.

\begin{tabular}{lcc}
\hline Material & Composition & Manufacturer \\
Portland & $\begin{array}{c}\text { Tricalcium silicate, dicalcium } \\
\text { silicate, iron-calcium aluminate, } \\
\text { calcium sulfate, tricalcium } \\
\text { aluminate, calcium carbonate, } \\
\text { magnesium oxide, calcium oxide }\end{array}$ & Votorantim, SP, Brazil \\
Bismuth oxide & Bismuth oxide & Sigma Aldrich, St Louis, \\
Zirconium oxide & Zirconium oxide & Sigma Aldrich, St Louis, \\
Calcium tungstate & MO \\
$\begin{array}{l}\text { Zinc oxide and } \\
\text { eugenol }\end{array}$ & Calcium tungstate & Sigma Aldrich, St Louis, \\
Powder: $\mathrm{ZnO}$ & MO \\
\hline
\end{tabular}

TABLE 2: Strains used as indicator of antimicrobial activity, their source, and morphotype.

\begin{tabular}{lcc}
\hline Microorganisms & Source & Morphotype \\
\hline Micrococcus luteus & ATCC 9341 & Gram-positive cocci \\
Streptococcus mutans & ATCC 25175 & Gram-positive cocci \\
Enterococcus faecalis & ATCC 29212 & Gram-positive cocci \\
Pseudomonas aeruginosa & ATCC 27853 & Gram-negative bacilli \\
Candida albicans & ATCC10231 & yeast \\
\hline
\end{tabular}

observed the presence of E. faecalis was $40.6 \%$ in root canals from 32 adults undergoing retreatment for periapical lesions after endodontic treatment performed at least 2 years previously.

Ozbek et al. [14] investigate the presence of E. faecalis in primary endodontic infections and failed endodontic treatment, suggesting the presence of this microorganism in not less than $61 \%$ of all endodontic infections.

Important factors should be taken into consideration when evaluating materials using the agar diffusion test, such as the physicochemical properties of the material; its speed and rate of diffusion [15]; the concentration of the antimicrobial agent; the composition, $\mathrm{pH}$, and thickness of the culture medium. Moreover, this method requires careful standardization of inoculum density, culture medium contents, agar viscosity, and number/size of the specimens present on each dish [16]. Other disadvantages of this test are the need for substances to be diffused in agar prior to analysis and the difficulties of measuring the zones of microbial growth inhibition [17]. Furthermore, this technique presents relatively low sensitivity and is semiquantitative, being unable to distinguish between bactericidal and bacteriostatic properties of the materials [18]. Despite these limitations, ADT is a useful method for preliminary evaluation of the antimicrobial effect of different substances.

Preincubation for 2 hours allows substances to diffuse in the agar gel, producing zones of microbial growth inhibition [19]. Triphenyl tetrazolium chloride (TTC), which was added to the culture medium, is a redox indicator of cellular respiration in growing microorganisms. With the addition of TTC, the medium turns red in the presence of viable microorganisms that grew on the plates [20], facilitating the visualization of zones of inhibition.

Our results show that all materials evaluated display antimicrobial action, producing zones of inhibition against all microbial strains. The samples of Portland cement combined with radiopacifying agents did not significantly differ from each other or from pure PC, confirming that none of the radiopacifiers interfered with this property. In the present study, zinc oxide and eugenol cement was used as positive control of antimicrobial activity against all strains. The antibacterial action of this cement is related to the presence of eugenol [21], which presents powerful bactericidal action by inhibiting cell growth and respiration, even at low concentrations. However, at high concentrations, eugenol is cytotoxic, inhibiting white cell chemotaxis, synthesis of prostaglandins, and nerve activity [22].

Portland cement-based materials are basically calcium oxides, which form calcium hydroxide when mixed with water. Calcium hydroxide is known to induce $\mathrm{pH}$ rise by dissociation of calcium and hydroxyl ions, as demonstrated by Hungaro Duarte et al. [23]. Other investigations have linked the antimicrobial action of MTA to its high $\mathrm{pH}$ [24]. However, it has been demonstrated that several endodontic microorganisms may be killed under conditions that are not $\mathrm{pH}$ mediated [25].

All samples of pure Portland cement, as well as PC combined with radiopacifying substances, promoted alkaline $\mathrm{pH}$ in all experimental periods (12, 24, 48, and 72 hours), with no statistical differences between the groups. This finding indicates that none of the radiopacifiers affected this property of PC. Camilleri [26] reported similar results 
TABle 3: Means and standard deviations of the inhibition zones values (in millimeters)*.

\begin{tabular}{|c|c|c|c|c|c|}
\hline & $\mathrm{PC}$ & $\mathrm{PC}+\mathrm{OBi}$ & $\mathrm{PC}+\mathrm{OZr}$ & $\mathrm{PC}+\mathrm{CT}$ & $\mathrm{ZOE}$ \\
\hline E. faecalis & $9 \pm 0$ & $8 \pm 0$ & $8 \pm 0$ & $8 \pm 0$ & $10 \pm 0$ \\
\hline P. aeruginosa & $12 \pm 0$ & $12.3 \pm 0.57$ & $10.6 \pm 2.30$ & $11 \pm 1.73$ & $24.6 \pm 1.15$ \\
\hline C. albicans & $23.6 \pm 1.15$ & $24 \pm 1$ & $22.3 \pm 0.57$ & $22.3 \pm 0.57$ & $25.6 \pm 2.08$ \\
\hline S. mutans & $11 \pm 0$ & $10.6 \pm 0.57$ & $10.6 \pm 0.57$ & $10.3 \pm 0.57$ & $12 \pm 1$ \\
\hline M. luteus & $31.6 \pm 0.57$ & $31.3 \pm 0.57$ & $30 \pm 1$ & $30 \pm 1$ & $34.3 \pm 1.15$ \\
\hline
\end{tabular}

${ }^{*}$ Means of the triplicate assays.

PC: Portland cement, OBi: bismuth oxide, OZr: zirconium oxide, CT: calcium tungstate, ZOE: zinc oxide and eugenol cement.

TABLE 4: Means and standard deviations of $\mathrm{pH}$ values for the different materials and periods.

\begin{tabular}{cccccc}
\hline & PC & PC + OBi & PC + OZr & PC + CT & ZOE \\
\hline $12 \mathrm{~h}$ & $10.24 \pm 0.05^{\mathrm{A}}$ & $10.20 \pm 0.21^{\mathrm{A}}$ & $10.21 \pm 0.12^{\mathrm{A}}$ & $10.23 \pm 0.07^{\mathrm{A}}$ & $7.484 \pm 0.41^{\mathrm{B}}$ \\
$24 \mathrm{~h}$ & $10.20 \pm 0.08^{\mathrm{A}}$ & $10.21 \pm 0.17^{\mathrm{A}}$ & $10.20 \pm 0.13^{\mathrm{A}}$ & $10.24 \pm 0.06^{\mathrm{A}}$ & $7.444 \pm 0.34^{\mathrm{B}}$ \\
$48 \mathrm{~h}$ & $10.23 \pm 0.08^{\mathrm{A}}$ & $10.30 \pm 0.15^{\mathrm{A}}$ & $10.22 \pm 0.14^{\mathrm{A}}$ & $10.26 \pm 0.08^{\mathrm{A}}$ & $7.346 \pm 0.31^{\mathrm{B}}$ \\
$72 \mathrm{~h}$ & $10.22 \pm 0.08^{\mathrm{A}}$ & $10.28 \pm 0.17^{\mathrm{A}}$ & $10.21 \pm 0.13^{\mathrm{A}}$ & $10.23 \pm 0.10^{\mathrm{A}}$ & $7.325 \pm 0.30^{\mathrm{B}}$ \\
\hline
\end{tabular}

Same letters within the same period of time indicate statistically similar results $(P>0.05)$.

PC: Portland cement, OBi: bismuth oxide, OZr: zirconium oxide, CT: calcium tungstate, ZOE: zinc oxide and eugenol cement.

for Portland cement combined with different radiopacifying substances, such as barium sulfate $\left(\mathrm{BaSO}_{4}\right)$, gold $(\mathrm{Au})$, and silver/tin $(\mathrm{Ag} / \mathrm{Sn})$, and observed that none of these agents affected the alkalinizing properties of pure Portland cement.

$\mathrm{pH}$ values near 12 are known to inhibit the activity of several microorganisms, including resistant bacteria such as Enterococcus faecalis [27]. Despite the fact that smaller zones of inhibition were observed for this strain, antimicrobial activity against $E$. faecalis was still detected for all cements tested, similarly to the results reported by Estrela et al. [28]. Contrastingly, other authors have reported the lack of antibacterial activity of Portland cement and of MTA against E. faecalis $[22,29]$. In an attempt to enhance the antimicrobial action of MTA, replacement of the water in the mixture with other liquids, such as $2 \%$ chlorhexidine, has been suggested [30]. Addition of antimicrobial substances to MTA is likely to improve its antibacterial action, but might negatively affect other properties of the cement [2]. A recent study [31] showed that association of MTA with silverzeolite improves the antimicrobial action of MTA against several bacterial strains, including E. faecalis. However, as mentioned above, it is important to investigate whether these substances affect the physicochemical properties of the cement. Moreover, the limitations of in vitro testing of antimicrobial agents should be taken into consideration.

\section{Conclusion}

Considering the methodology employed and the results obtained, it was concluded that the addition of radiopacifiers (bismuth oxide, calcium tungstate, and zirconium oxide) to Portland cement did not interfere with its antimicrobial action and $\mathrm{pH}$. All associations evaluated presented similar results among each other and in comparison with pure Portland cement.

\section{Conflict of Interests}

The authors declare that they have no conflict of interests.

\section{Disclosure}

There were no external sources of funding for the present study.

\section{References}

[1] M. Torabinejad and T. R. Pitt Ford, "Root end filling materials: a review," Endodontics and Dental Traumatology, vol. 12, no. 4, pp. 161-178, 1996.

[2] M. Parirokh and M. Torabinejad, "Mineral trioxide aggregate: a comprehensive literature review-part I: chemical, physical, and antibacterial properties," Journal of Endodontics, vol. 36, no. 1, pp. 16-27, 2010.

[3] M. Parirokh and M. Torabinejad, "Mineral trioxide aggregate: a comprehensive literature review-part III: clinical applications, drawbacks, and mechanism of action," Journal of Endodontics, vol. 36, no. 3, pp. 400-413, 2010.

[4] L. A. Dreger, W. T. Felippe, J. F. Reyes-Carmona, G. S. Felippe, E. A. Bortoluzzi, and M. C. Felippe, "Mineral trioxide aggregate and portland cement promote biomineralization in vivo," Journal of Endodontics, vol. 38, no. 3, pp. 324-329, 2012.

[5] M. G. de Oliveira, C. B. Xavier, F. F. Demarco, A. L. B. Pinheiro, A. T. Costa, and D. H. Pozza, "Comparative chemical study of MTA and Portland cements," Brazilian Dental Journal, vol. 18, no. 1, pp. 3-7, 2007.

[6] K. S. Coomaraswamy, P. J. Lumley, and M. P. Hofmann, "Effect of bismuth oxide radioopacifier content on the material properties of an endodontic Portland cement-based (MTAlike) system," Journal of Endodontics, vol. 33, no. 3, pp. 295298, 2007.

[7] K. Asakura, H. Satoh, M. Chiba et al., "Genotoxicity studies of heavy metals: lead, bismuth, indium, silver and antimony," 
Journal of Occupational Health, vol. 51, no. 6, pp. 498-512, 2009.

[8] E. A. Bortoluzzi, J. M. Guerreiro-Tanomaru, M. TanomaruFilho, and M. A. H. Duarte, "Radiographic effect of different radiopacifiers on a potential retrograde filling material," Oral Surgery, Oral Medicine, Oral Pathology, Oral Radiology and Endodontology, vol. 108, no. 4, pp. 628-632, 2009.

[9] A. L. Gomes Cornélio, L. P. Salles, M. Campos Da Paz, J. A. Cirelli, J. M. Guerreiro-Tanomaru, and M. Tanomaru Filho, "Cytotoxicity of Portland cement with different radiopacifying agents: a cell death study," Journal of Endodontics, vol. 37, no. 2, pp. 203-210, 2011.

[10] G. De-Deus, V. Petruccelli, E. Gurgel-Filho, and T. CoutinhoFilho, "MTA versus Portland cement as repair material for furcal perforations: a laboratory study using a polymicrobial leakage model," International Endodontic Journal, vol. 39, no. 4, pp. 293-298, 2006.

[11] M. Hasan Zarrabi, M. Javidi, M. Naderinasab, and M. Gharechahi, "Comparative evaluation of antimicrobial activity of three cements: new endodontic cement (NEC), mineral trioxide aggregate (MTA) and Portland," Journal of Oral Science, vol. 51, no. 3, pp. 437-442, 2009.

[12] X. Zhu, Q. Wang, C. Zhang, G. S. P. Cheung, and Y. Shen, "Prevalence, phenotype, and genotype of Enterococcus faecalis isolated from saliva and root canals in patients with persistent apical periodontitis," Journal of Endodontics, vol. 36, no. 12, pp. 1950-1955, 2010.

[13] M. Nagayoshi, T. Nishihara, K. Nakashima, S. Iwaki, K. K. Chen, and M. Terashita, "Bactericidal effects of diode laser irradiation on Enterococcus faecalis using periapical lesion defect model," ISRN Dentistry, vol. 2011, Article ID 870364, 2011.

[14] S. M. Ozbek, A. Ozbek, and A. S. Erdogan, "Analysis of Enterococcus faecalis in samples from Turkish patients with primary endodontic infections and failed endodontic treatment by real-time PCR SYBR green method," Journal of Applied Oral Science, vol. 17, no. 5, pp. 370-374, 2009.

[15] F. K. Çobankara, H. C. Altinöz, O. Erganiş, K. Kav, and S. Belli, "In vitro antibacterial activities of root-canal sealers by using two different methods," Journal of Endodontics, vol. 30, no. 1, pp. 57-60, 2004.

[16] C. Estrela, L. L. Bammann, F. C. Pimenta, and J. D. Pécora, "Control of microorganisms in vitro by calcium hydroxide pastes," International Endodontic Journal, vol. 34, no. 5, pp. 341-345, 2001.

[17] E. Bodrumlu and T. Alaçam, "Evaluation of antimicrobial and antifungal effects of iodoform-integrating gutta-percha," Journal of the Canadian Dental Association, vol. 72, no. 8, pp. 733-733, 2006.

[18] R. S. Tobias, "Antibacterial properties of dental restorative materials: a review," International Endodontic Journal, vol. 21, no. 2, pp. 155-160, 1988.

[19] J. M. Tanomaru, M. Tanomaru-Filho, J. Hotta, E. Watanabe, and I. Y. Ito, "Antimicrobial activity of endodontic sealers based on calcium hydroxide and MTA," Acta Odontológica Latinoamericana, vol. 21, no. 2, pp. 147-151, 2008.

[20] W. J. Begue and R. M. Kline, "The use of tetrazolium salts in bioauthographic procedures," Journal of Chromatography A, vol. 64, no. 1, pp. 182-184, 1972.

[21] M. R. Leonardo, L. A. B. Da Silva, M. Tanomaru Filho, K. C. Bonifácio, and I. Y. Ito, "In vitro evaluation of antimicrobial activity of sealers and pastes used in endodontics," Journal of Endodontics, vol. 26, no. 7, pp. 391-394, 2000.
[22] C. R. Sipert, R. P. Hussne, C. K. Nishiyama, and S. A. Torres, "In vitro antimicrobial activity of Fill Canal, Sealapex, Mineral Trioxide Aggregate, Portland cement and EndoRez," International Endodontic Journal, vol. 38, no. 8, pp. 539-543, 2005.

[23] M. A. Hungaro Duarte, A. C. C. De Oliveira Demarchi, J. C. Yamashita, M. C. Kuga, and S. De Campos Fraga, "pH and calcium ion release of 2 root-end filling materials," Oral Surgery, Oral Medicine, Oral Pathology, Oral Radiology, and Endodontics, vol. 95, no. 3, pp. 345-347, 2003.

[24] K. Al-Hezaimi, T. A. Al-Shalan, J. Naghshbandi, S. Oglesby, J. H. S. Simon, and I. Rotstein, "Antibacterial effect of two Mineral Trioxide Aggregate (MTA) preparations against Enterococcus faecalis and Streptococcus sanguis in vitro," Journal of Endodontics, vol. 32, no. 11, pp. 1053-1056, 2006.

[25] M. Zehnder, E. Söderling, J. Salonen, and T. Waltimo, "Preliminary evaluation of bioactive glass S53P4 as an endodontic medication in vitro," Journal of Endodontics, vol. 30, no. 4, pp. 220-224, 2004.

[26] J. Camilleri, "Evaluation of the physical properties of an endodontic Portland cement incorporating alternative radiopacifiers used as root-end filling material," International Endodontic Journal, vol. 43, no. 3, pp. 231-240, 2010.

[27] C. P. McHugh, P. Zhang, S. Michalek, and P. D. Eleazer, "pH required to kill Enterococcus faecalis in vitro," Journal of Endodontics, vol. 30, no. 4, pp. 218-219, 2004.

[28] C. Estrela, L. L. Bammann, C. R. Estrela, R. S. Silva, and J. D. Pécora, "Antimicrobial and chemical study of MTA, Portland cement, calcium hydroxide paste, Sealapex and Dycal," Brazilian Dental Journal, vol. 11, no. 1, pp. 3-9, 2000.

[29] C. S. Ribeiro, F. A. Kuteken, R. Hirata, and M. F. Z. Scelza, "Comparative evaluation of antimicrobial action of MTA, calcium hydroxide and portland cement," Journal of Applied Oral Science, vol. 14, no. 5, pp. 330-333, 2006.

[30] D. M. Holt, J. D. Watts, T. J. Beeson, T. C. Kirkpatrick, and R. E. Rutledge, "The anti-microbial effect against Enterococcus faecalis and the compressive strength of two types of Mineral Trioxide Aggregate mixed with sterile water or $2 \%$ chlorhexidine liquid," Journal of Endodontics, vol. 33, no. 7, pp. 844-847, 2007.

[31] M. E. Odabaş, Ç. Çinar, G. Akça, I. Araz, T. Ulusu, and H. Yücel, "Short-term antimicrobial properties of mineral trioxide aggregate with incorporated silver-zeolite," Dental Traumatology, vol. 27, no. 3, pp. 189-194, 2011. 


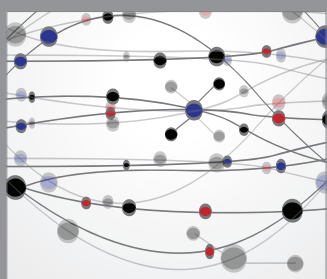

The Scientific World Journal
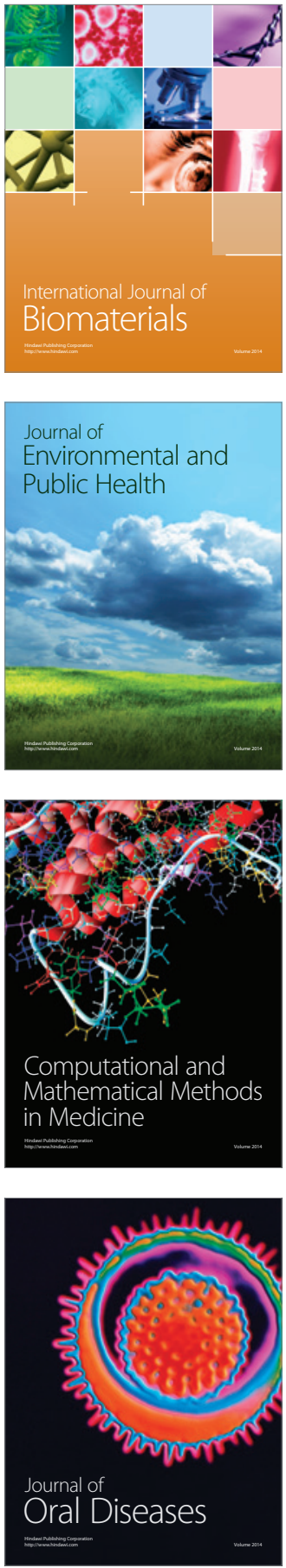
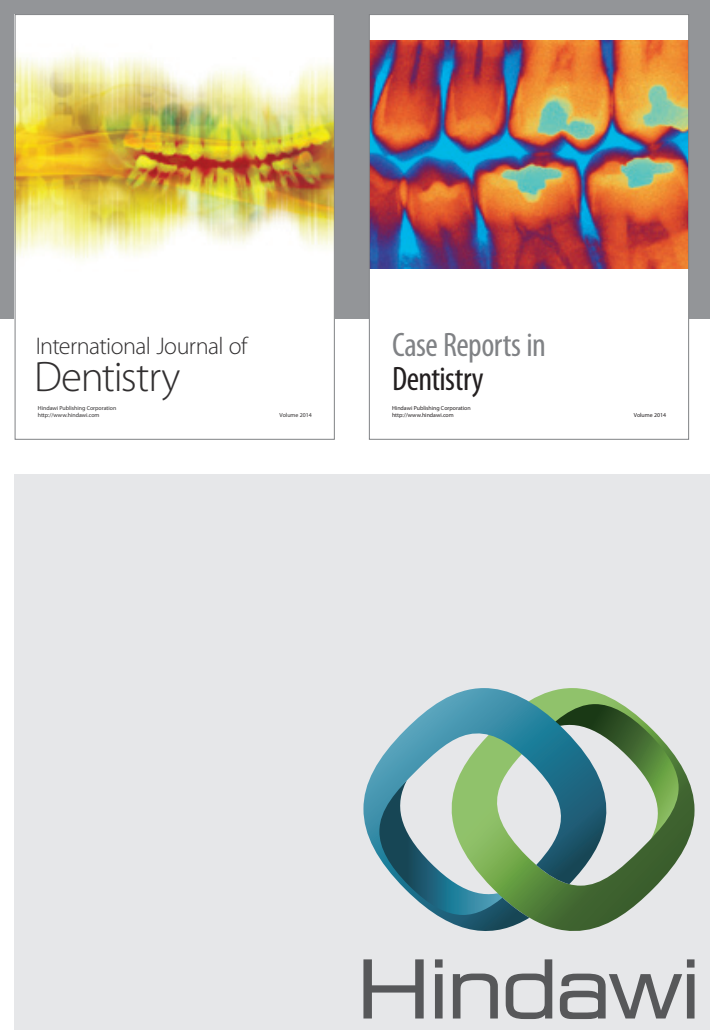

Submit your manuscripts at

http://www.hindawi.com
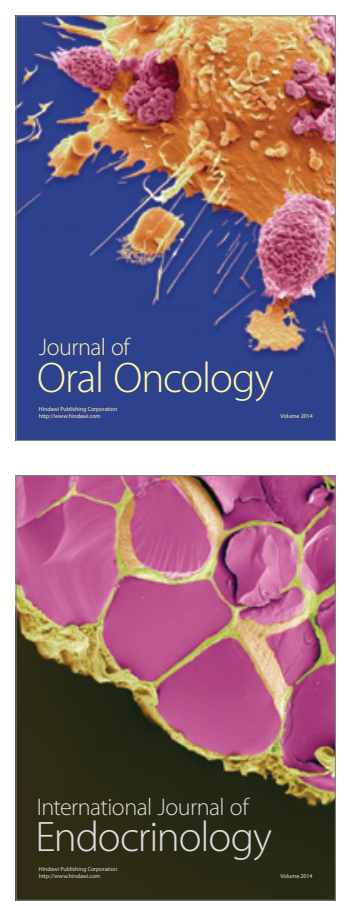
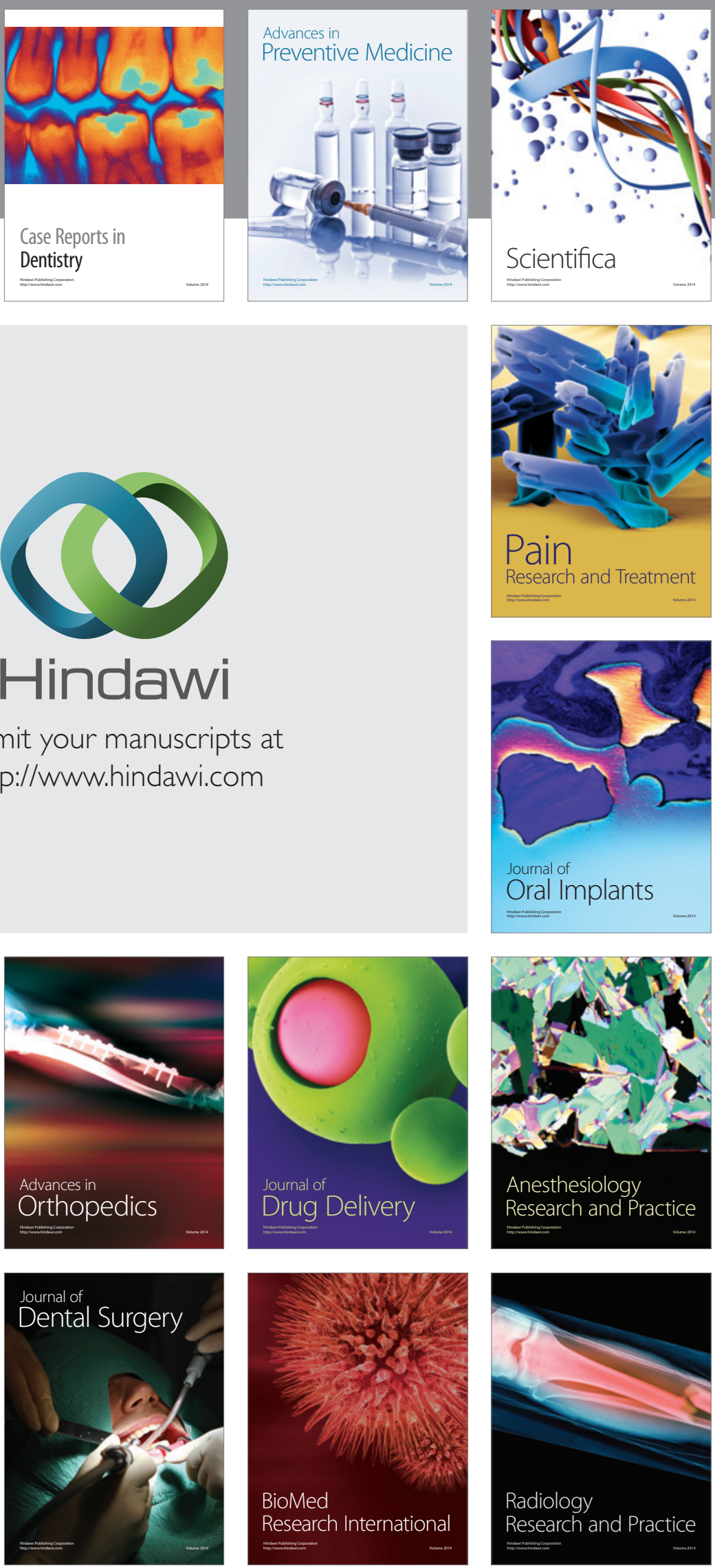